Cilt: 2

Sayı: 1

Sayfa: $71-80$

Mayıs 2013

\section{Kentsel alanların WorldView-2 uydu görüntülerinden makine öğrenme algoritmaları kullanılarak tematik haritalanması}

\author{
Dilek Koc-San*
}

Uzay Bilimleri ve Teknolojileri Bölümü Akdeniz Üniversitesi, Antalya 07058, Türkiye

\section{Özet}

Kentsel alanların uzaktan algılama görüntülerinden görüntü sinıflandırma teknikleri kullanılarak izlenmesi ve haritalanmasl şehir ve bölge plancllarl ve belediyeler için önemlidir. Yüksek çözünürlüklü uydu görüntüleri arazi-kullanımı/arazi-örtüsü haritalarının elde edilmesinde önemli veri kaynaklarıdır. Bu makalede, makine ögrenme algoritmalarından rastgele orman ve destek vektör makineleri sinıflandırmaları kullanılarak WorldView-2 uydu görüntülerinden kentsel tematik haritalar elde edilmiştir. Bu sinıflandirmaların performansları seçilen farklı kentsel karakteristiklere sahip dört test alanında değerlendirilmiş ve karşılaştırılmıştır. Dört test alanı için elde edilen görsel ve nicel sonuçlar, makine öğrenme algoritmalarının kentsel tematik haritalamada verimliliğini göstermektedir. Rastgele orman sinıflandırması kullanıldığında sinıflandırma doğrulukları 89.92 ile 96.38 değerleri arasında ve kappa değerleri 0.8790 ile 0.9566 değerleri arasında hesaplanmıştır ki bu değerler oldukça yüksektir. Benzer şekilde, destek vektör makineleri sinıflandırması kullanıldığında sınıflandırma doğrulukları 91.98 ile 96.07 değerleri arasında ve kappa değerleri 0.9038 ile 0.9528 değerleri arasında hesaplanmıştır. Sonuçlar, ayrıca farklı test alanları için elde edilen farklı sinıflandırma doğruluklarının seçilen kentsel dokuların özellikleriyle ilişkili olduğunu göstermektedir.

Anahtar Sözcükler

Kentsel tematik haritalama, Rastgele orman sinıflandırması, Destek vektör makineleri sinıflandırması, WorldView-2, Antalya

\begin{abstract}
Thematic mapping of urban areas from WorldView-2 satellite imagery using machine learning algorithms

Monitoring and mapping urban areas from remote sensing imagery using image classification techniques are important for urban and regional planners and municipalities. High resolution satellite images are essential data sources for the generation of urban land-use/land-cover maps. In this paper, urban thematic maps are generated from WorldView-2 satellite images using machine learning algorithms, namely random forest and support vector machines classifiers. The performances of these classifiers are evaluated and compared using four test areas that have different urban characteristics. The obtained visual and quantitative results for four test areas indicate the effectiveness of the machine learning algorithms in urban thematic mapping. The overall accuracies were computed in the range of 89.92 and 96.38 and overall kappa values were computed in the range of 0.8790 and 0.9566 for random forest classifier, which are considerably high. Similarly, for support vector machines classifier, the overall accuracies were computed in the range of 91.98 and 96.07 and overall kappa values were computed in the range of 0.9038 and 0.9528 . The results also show that different classification accuracies for different test areas are related to the properties of the selected urban patterns.
\end{abstract}

Keywords

Urban thematic mapping, Random forest classifier, Support vector machines classifier, WorldView-2, Antalya

\footnotetext{
** Hakemli değerlendirme sürecinden geçerek, Jeodezi ve Jeoinformasyon Dergisi'nde yayına kabul edilen ve asıl yazı dili İngilizce olan "Thematic Mapping of Urban Areas from WorldView-2 Satellite Imagery Using Machine Learning Algorithms " başıklı eserin Türkçe diline çevirisidir. Çeviren; Dilek Koc-San, Eyup Sopaci

* Sorumlu Yazar: Tel: +90 (242) 3102340 Fax: +90 (242) 2278911

E-mail: dkocsan@akdeniz.edu.tr (Koc-San D.), eyupsopaci@gmail.com (Sopaci, Eyup)
} 


\section{Giriş}

Arazi-kullanımını/örtüsünü uzaktan algılama verilerinden tespit etmek önemli bir araştırma alanıdır ve uzaktan algılama topluluğunda büyük ilgi görmektedir. Kent planlamada güncel arazi kullanımı/örtüsü haritalarına büyük ihtiyaç vardır. $\mathrm{Bu}$ haritalar kentsel alanların belirlenmesi, kentsel tesis dağılımları, kentsel değişimlerinin izlenmesi ve kentsel haritaların güncellenmesi için önemli veri kaynaklarıdır. Arazi-örtüsü haritalarında tespit edilen kent objeleri kent planlama ve yönetimi, kent bilgi sistemleri, CBS uygulamaları ve 3B kent modelleme gibi kentle ilgili çeşitli uygulamalar için oldukça önemlidir.

Kentsel tematik haritalama için uzaktan algılama görüntüsü kullanımı hızlı, hassas ve uygun maliyetli bir yöntemdir. Hassas kent alanı haritalama için yüksek çözünürlüklü görüntüler ( $\leq 5 \mathrm{~m})$ gereklidir (Welch 1982; Ridd 1995). Son zamanlardaki teknolojik gelişmelerle birlikte, yüksek konumsal çözünürlüklü uydu görüntüleri artarak ve etkin bir şekilde kent alanlarının hassas ve güvenilir arazi-örtüsü haritalarını üretmek için kullanılmaktadır. Yüksek konumsal çözünürlüklü uydu sensörleri tarafindan elde edilen uzaktan algılama görüntüleri arazi-örtüsü sınıflandırması için önemli veri kaynaklarıdır. Bunların arasında, WorldView-2 uydu görüntüsü sekiz bandı ve artırılmış doğruluğu ile öne çıkmaktadır. Kentsel arazi-örtüsü haritalama için yüksek çözünürlüklü uydu/ hava görüntüsü kullanılan çalışmalar vardır. Yonezawa (2007) Quickbird görüntüsünden kentsel arazi-örtüsü tespiti için spektral açı eşleyici algoritması ile birleştirilmiş en büyük olasılık sınıflandırmasını kullanmış ve önerilen algoritmanın sınıflandırma doğruluğunu artırdığı sonucuna varmıştır. Huang vd. (2007) QuickBird uydu görüntüsü kullanarak kentsel alanlarda detay çıkarımı için en büyük olasılık, geri yayılım sinir ağı, olasılık sinir ağı ve destek vektör makineleri sınıflandırmalarını kıyaslamıştır. Pacifici vd. (2009) yapay sinir ağı sınıflandırmasını QuickBird ve WorldView-1 uydu görüntülerinden kentsel alan sınıflandırması için kullanmıştır. Chen vd. (2012) yüksek çözünürlüklü görüntü sınıflandırması için geliştirilmiş nesne-tabanlı sınıflandırma algoritması önermiş ve bu algoritmayı IKONOS uydu görüntüleri üzerinde uygulamıştır. Diğer taraftan kentsel tematik haritalama için, yüksek çözünürlüklü görüntüye ek olarak LIDAR verilerini kullanan çalışmalar da vardır (Guan vd. 2013; Berger vd. 2013).

Arazi-kullanımı/örtüsü sınıflandırmasında kullanılabilen, kontrolsüz sınıflandırma, parametrik kontrollü sınıflandırma, parametrik olmayan kontrollü sınıflandırma gibi birçok s1nıflandırma teknikleri vardır. Makine öğrenme algoritmaları parametrik olmayan kontrollü sınıflandırma teknikleridir ve göreceli olarak uzaktan algılamada yeni bir çalışma alanıdır. Bunlar arasında, toplu öğrenme teknikleri ve destek vektör makineleri (DVM) sinıflandırması uzaktan algılama uygulamalarında büyük dikkat çekmektedir. Torbalama ve hızlandırma gibi toplu öğrenme teknikleri karar ağaçları seti kullandığından genel olarak tekli sınıflandırmadan daha iyi performans sağlar (Breiman 1996; Gislason vd. 2006; Rodriguez-Galiano vd. 2012). Torbalama ile kıyaslandığında, hızlandırma daha doğru sonuçlar verir. Ancak hesaplamalar açısından torbalama hızlandırmadan daha etkindir. Rastgele orman (RO) sınıflandırıcı geliştirilmiş torbalama algoritması kullanır. RO sınıflandırıcı hesaplamalar açısından etkindir ve genellikle diğer sınıflandırıcılardan daha yüksek performans sağlar (Waske vd. 2012). Diğer taraftan, DVM sinıflandırıcı istatistik öğrenme teoremi temellidir. Önceleri ikili sınıflan- dırma için önerilmiş ve sonra çok sınıflı sınıflandırma problemi için geliştirilmiştir. DVM sınıflandırması son zamanlarda uzaktan algılama araştırma alanında umut verici ve dikkat çekici sonuçlar sağlayarak kullanılmaktadır.

Literatürde RO sınıflandırıcıyı diğer sınıflandırma teknikleriyle karşılaştıran çalışmalar bulunmaktadır. Waske ve Braun (2009) RO sınıflandırma algoritmasını karar ağacı, en büyük olasılık, hızlandırılmış karar ağacı ile çok bantlı SAR görüntüsünden tarımsal alanların arazi kullanım haritalaması için karşılaştırmış ve RO'nun diğer sınıflandırma algoritmalarından daha başarılı olduğunu saptamıştır. Rodriguez-Galiano ve Chica-Rivas (2012) tarafindan yürütülen çalışmada, sınıflandırma ağaçları, yapay sinir ağları, destek vektör makineleri ve rastgele orman yöntemlerinin performansları değerlendirilmiştir ve RO'nun diğer sınıflandırma tekniklerinden daha iyi sınıflandırma doğruluğu sağladığı sonucuna ulaşılmıştır. Palsson vd. (2012), RO ve DVM sınıflandırma tekniklerini kentsel uydu görüntülerini sınıflandırmada kullanmış ve neredeyse her durumda RO sınıflandırıcının daha iyi sınıflandırma doğruluğu sağladığını göstermiştir. Akar ve Güngör (2012) tarafından yürütülen çalışmada RO sınıflandırma sonuçları Gentle AdaBoost, DVM ve en büyük olasılık sınıflandırmaları ile kıyaslanmıştır. Yazarlar, RO sınıflandırmasının daha yüksek doğruluk sağladığını ortaya koymuşlardır.

DVM'nin diğer sınıflandırma tekniklerinden üstünlüğü önceki çalışmalarda ifade edilmiştir. Huang vd. (2002) DVM, en büyük olasılık, sinir ağı ve karar ağacı sınıflandırıcılarının performans kıyaslamalarını değerlendirmiș ve DVM yönteminin çoğu durumda daha yüksek doğruluk verdiğini bulmuştur. Kavzoglu ve Colkesen (2009) DVM ve en büyük olasılık sınıflandırıcılarını kıyaslamış ve DVM'nin en büyük olasılık sınıflandırıcısına göre üstünlük sağladığını bildirmiştir. Watanachaturaporn vd. (2008)'nin yaptığı çalışmada DVM sınıflandırıcı diğer yaygın sınıflandırıcılarla (en büyük olasılık, karar ağacı, geri yayılım sinir ağı ve radyal fonksiyon temelli ağ) kıyaslamıştır. Bu çalışmada, DVM'nin çok kaynaklı sınıflandırmalar için potansiyeli olduğu ifade edilmiştir. Bunun yanında, Waske vd. (2009), Sesnie vd. (2010), Dalponte vd. (2013) ve Koc-San (2013) taraflarından gerçekleştirilen çalışmalarda, DVM ve RO sınıflandırıcıları kıyaslanmıştır. Bu çalışmalarda, DVM sınıflandırma tekniği RO'ya göre nispeten daha iyi sonuçlar vermiştir. Diğer taraftan, RO ve DVM makine öğrenme algoritmalarının performanslarının neredeyse eşit olduğunu gösteren çalışmalar da vardır (Pal 2005; Waske vd. 2009).

$\mathrm{Bu}$ çalışmanın amacı WorldView-2 uydu görüntüleri kullanarak farklı karakterlere sahip kentsel alanların tematik haritalarını üretmektir. Makine öğrenme algoritmalarından Rastgele Orman (RO) ve Destek Vektör Makineleri'nin (DVM) kentsel tematik haritalama için performansları ve kullanılabilirliği araştırılmış ve karşılaştırılmıştır. Bu makale şu bölümlerden oluşmaktadır; Bölüm 2'de seçilen dört test bölgesi ve bu çalışmada kullanılan veriler tanımlanmıştır. Kentsel tematik harita üretimi için kullanılan yöntem bölüm 3'te açıklanmıştır. Daha sonra Bölüm 4'te araştırma sonuçları gösterilip tartışılmıştır. Son olarak, elde edilen sonuçlar bölüm 5'te verilmiştir.

\section{Test alanları ve kullanılan veriler}

Kentsel tematik haritalar üretmek için Türkiye'nin Antalya ilinde bulunan Muratpaşa, Konyaaltı ve Kepez ilçelerinden farklı karakterlere sahip dört test alanı seçilmiştir (Şekil 1). 
Test alanları farklı yoğunlukta kentsel alanları ve farklı şekilde, boyutta ve farklı çatılı binaları içermektedir. Seçilen ilk test alanı Muratpaşa ilçesinde Kaleiçi'nde (tarihi kent merkezi) yer almakta ve konut, ticaret ve turistik amaçlı kullanılan az katlı (bir-iki katlı) binaları içermektedir. İkinci test alanı Muratpaşa ilçesinde, kent merkezinde yer almakta ve orta ve yüksek katlı binaları içermektedir. Üçüncü test alanı orta ve yüksek katlı binaları içeren yeni gelişmiş yerleşim alanıdır ve Konyaaltı ilçesinde yer almaktadır. Son olarak dördüncü test alanı Kepez ilçesinde bulunmaktadır. Bu test alanında birbirine çok yakın az katlı binalar bulunmaktadır.
İlk test alanı geleneksel konut dokusuna sahiptir. İkinci ve üçüncü test alanları planlı ve düzenli gelişen yerleşim yerlerini içerirken, dördüncü test alanı plansız konut alanlarını içermektedir. Ek olarak, test alanlarının spektral karakterleri analiz edildiğinde birinci ve dördüncü test alanlarının çoğunlukla kiremit çatılı binalar içerdiği bunun yanında beton çatılı binaların da bulunduğu ifade edilebilir. Diğer taraftan, ikinci ve üçüncü test alanlarında çoğunlukla beton bina çatıları vardır. İkinci ve üçüncü test alanlarında yer alan binalar, birinci ve dördüncü test alanlarıyla karşılaştırıldığında boyutları daha büyük olduğundan daha avantajlıdır.

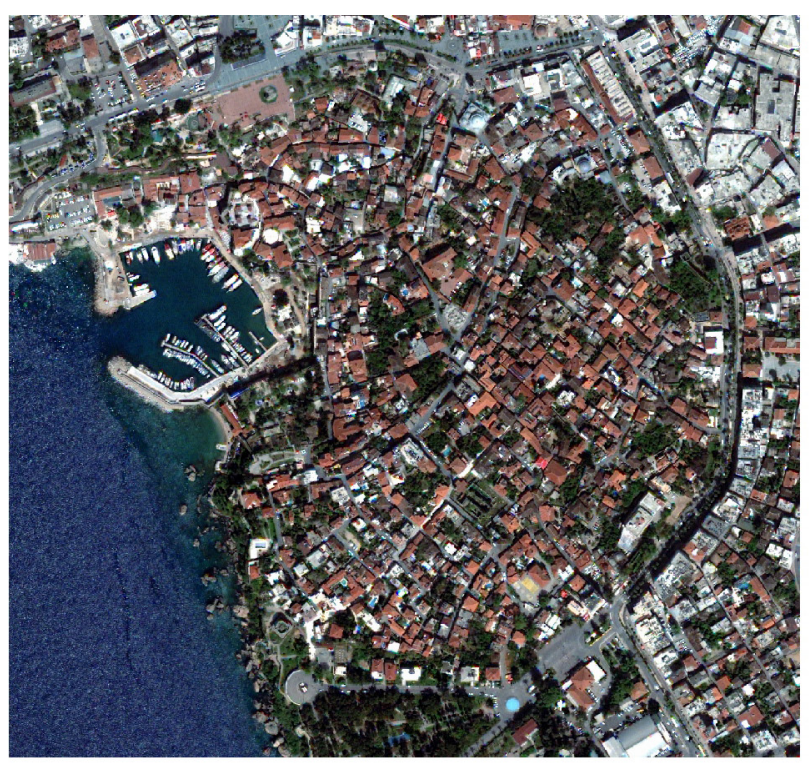

(a)

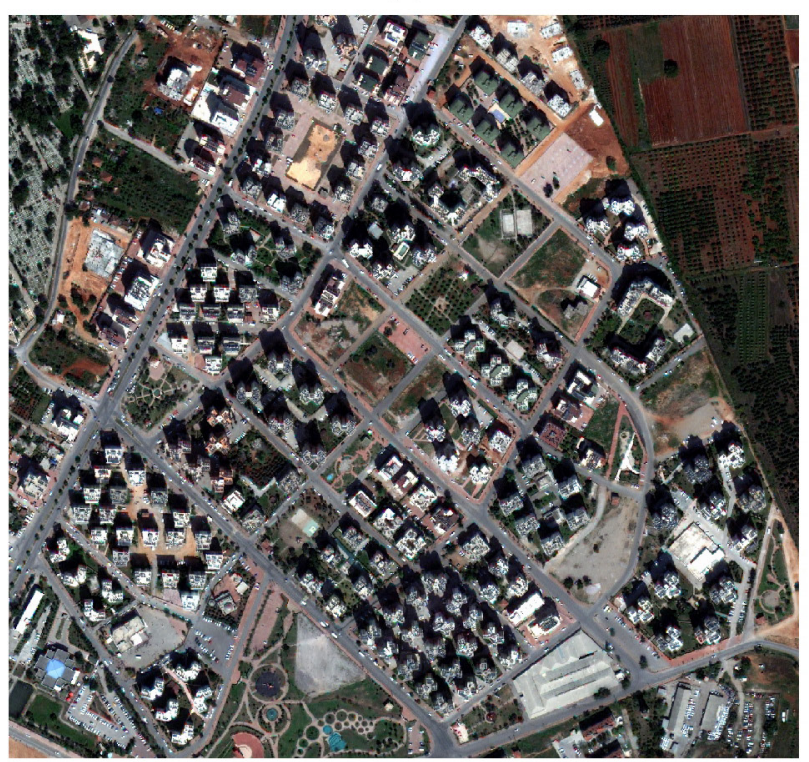

(c)

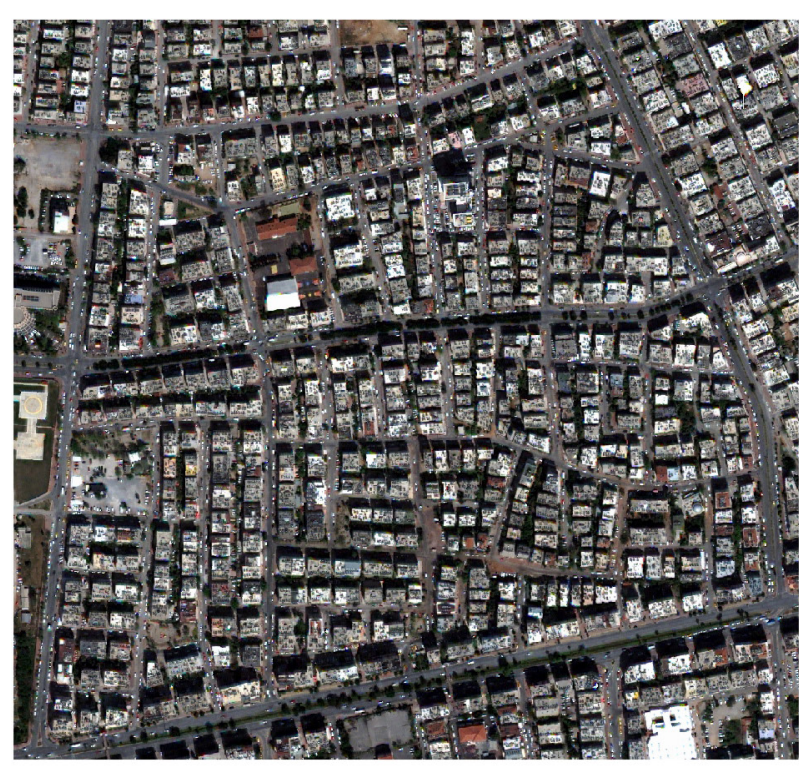

(b)

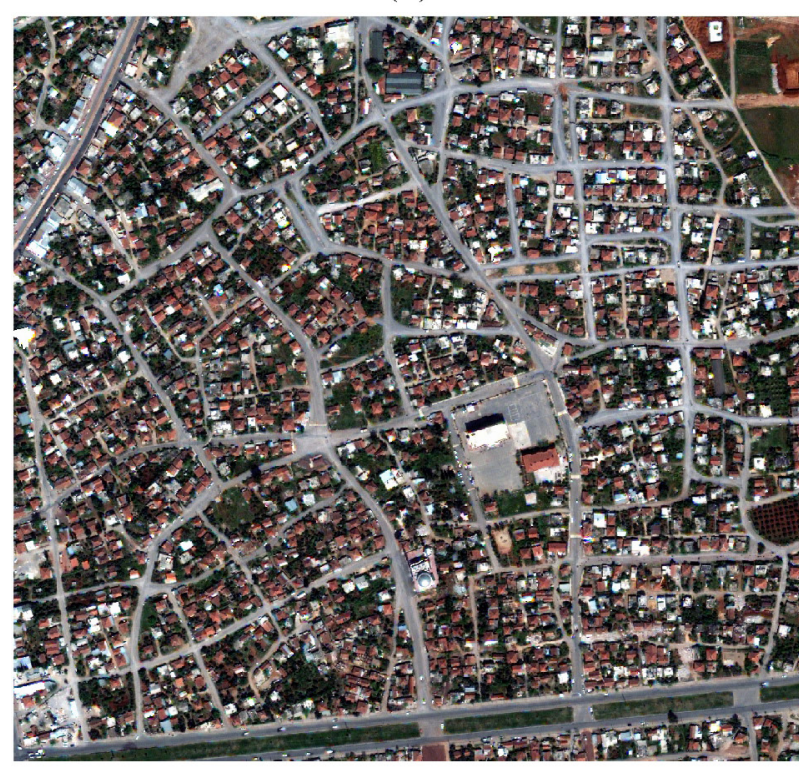

(d)

Şekil 1: Türkiye'nin Antalya ilinde bulunan test alanlarını kapsayan WorldView-2 uydu görüntülerinin gerçek renk bileşimi: Test Alanı I (a), Test Alanı II (b), Test Alanı III (c), ve Test Alanı IV (d). 
$\mathrm{Bu}$ çalışmada kullanılan veriler WorldView-2 pankromatik ve çok bantlı uydu görüntüleridir. WorldView-2 uydu görüntüsü, $0.5 \mathrm{~m}$ pankromatik ve $2 \mathrm{~m}$ çok bantlı konumsal çözünürlükle, mevcut uydu görüntüleri arasında en yüksek konumsal çözünürlüğe sahip uydu görüntülerinden biridir. Buna ek olarak WorldView-2 uydu görüntüsü 8 spektral bantlı (Sahil, Mavi, Yeşil, Sarı, Kırmızı, Kırmızı Kenar, Yakın Kızılötesi-1 ve Yakın Kızılötesi-2) ilk ticari yüksek çözünürlüklü uydu görüntüsüdür. Bu çalışmada kullanılan uydu görüntüleri 6 Nisan 2012 tarihlidir. WorldView-2 uydu görüntüleri geometrik doğrulukları DigitalGlobe tarafından yapılmış olarak satın alınmaktadır (Updike ve Comp, 2010; Oumar ve Mutanga, 2013). Ön işlemede, çok bantlı görüntü ile pankromatik görüntü PCI Geomatica 2013'ün PANSHARP2 (yüksek performanslı görüntü zenginleştirme) algoritması kullanılarak zenginleştirilmiş ve $0.5 \mathrm{~m}$ mekansal çözünürlüklü renkli görüntü (8bant) elde edilmiştir. Bu görüntü keskinleştirme algoritması, oldukça iyi keskinleştirme sonuçları ürettiği ve orijinal görüntülerin spektral karakterleri korunduğu için (PCI Software Users Manual 2013) bu çalışmada tercih edilmiştir.

\section{Yöntem}

\subsection{Eğitim ve test örneklerinin toplanması}

Görüntü sınıflandırmasını yapmak için öncelikle test alanlarındaki arazi örtüsü görsel olarak analiz edilerek her bir test alanı için sınıflar belirlenmiş ve sonra eğitim ve test örnekleri birbirinden bağımsız olarak toplanmıştır. Eğitim örnekleri, katmanlı rastgele örnekleme tekniği ile başlangıçta kabaca toplanan alanlardan seçilmiştir. Her bir sınıf için 500 eğitim örneği seçilmiştir. Buna ek olarak, yansız referans veri üretmek için test örnekleri eğitim örneklerinden farklı alanlardan toplanmıştır. Bu çalışmada her sınıf için 1000 test örneği toplanmıştır.

\subsection{Makine öğrenme algoritmaları kullanarak kentsel alanların tematik haritalanması}

Bu çalışmada, iki güçlü makine öğrenme algoritması, RO ve DVM, kentsel arazi-örtüsü haritalamada kullanılmıştır. Toplu öğrenme algoritmalarından RO sınıflandırıcı, Breiman (2001) tarafindan yeni ve umut vadeden bir sınıflandırma tekniği olarak önerilmiştir. RO sınıflandırıcının uzaktan algılama uygulamalarında kullanılması nispeten yenidir (Rodriguez-Galiano ve Chica-Rivas 2012). Bu sinıflandırmada toplu sinıflandırma için torbalama ve regresyon ağacı (CART) sınıflandırıcı kullanılır. Önyükleme kullanarak, eğitim örneklerinin üçte biri torba-dışı (out-of-bag) hata kestirimi ve kalan eğitim örnekleri de ağaç kurulumu için kullanılmıştır. RO sınıflandırmasında iki önemli parametre vardır; RO'yu üretmek için kullanılan ağaç sayısı (k) ve her devre düğümünü ayırmak için kullanılan değişken sayısı (m). Bu parametreler kullanıcı tarafından tanımlanmalıdır. RO sınıflandırmasına ilişkin ayrıntılar Breiman (2001) de bulunabilir.

$\mathrm{Bu}$ çalışmada, RO sınıflandırması, uzaktan algılanmış görüntü için IDL tabanlı rastgele orman sınıflandırma aracı olan ImageRF kullanılarak yapılmıştır (Jakimow vd. 2012; Waske vd. 2012). Sinıflandırmada $k$ ve $m$ değerlerine, sırasıyla 100-1000 arasında 100'er artış ve 1-8 arasında 1'er artış ile test edilerek karar verilmiştir. Her test alanı için en iyi parametreler torba dışı doğrulukları, genel doğruluklar ve hesap süreleri değerlendirilerek belirlenmiştir. I. Test alanı için en uygun $\mathrm{k}$ ve $\mathrm{m}$ değerleri sırasıyla 100 ve 2 olarak seçilmiştir. II. Test alanı için aynı değerler sırasıyla 700 ve 2 olarak belirlenmiştir. III. Test alanı için, en uygun $\mathrm{k}$ ve $\mathrm{m}$ değerleri sırasıyla 900 ve 1 olarak seçilmiştir. Son olarak IV. Test alanı için $\mathrm{k}$ ve m değerleri sırasıyla 300 ve 3 olarak belirlenmiştir. RO sınıflandırması boyunca, Gini katsayısı katışıklık (impurity) fonksiyonu olarak kullanılmıştır.

DVM sınıflandirıcının temelleri Vapnik (1995) tarafından ortaya koyulmuştur. DVM sınıflandırmada amaç sınıfları ayıracak en uygun ayrıştırıcı hiperdüzlemi bulmaktır. Bu amaç için önce eğitim örnekleri özellik vektörü olarak tan1tılır. Lineer olarak ayrışmama durumunda, özellik vektörleri özellik uzayına kernel fonksiyonu yardımıyla dönüştürülür. Sınıf dağılımlarının kenarlarında bulunan destek vektörleri hiperdüzlemi oluşturmak için kullanılır. DVM sınıflandırmas1 hakkında detaylı bilgi Vapnik (1995) ve Wang (2005)'de bulunabilir. DVM sinıflandırmasında penaltı parametresinin belirlenmesi, kernel metodunun ve ilişkili parametrelerin seçimi önemlidir.

Bu çalışmada, çiftli DVM sınıflandırma Geomatics Lab of Humboldt-Universitat zu Berlin tarafından geliştirilen ImageSVM aracı kullanarak yapılmıştır (Van der Linden vd. 2010; Rabe vd. 2010). DVM siniflandırmasinda kernel metodu olarak radyal temelli fonksiyon kullanılmıştır. En uygun gamma ve penaltı parametre değerleri 3 kat çapraz geçerlilik tekniği kullanarak belirlenmiştir. Her iki parametre de tüm test alanları için 0.0001-1000 değerleri aralığında test edilmiştir. Gamma değeri tüm test alanları için 0.0001 olarak belirlenmiştir. Ayrıca, en uygun penaltı parametre değeri Test Alanları I ve II için 10 olarak bulunurken, aynı parametre Test alanları III ve IV için 100 olarak seçilmiştir.

\subsection{Doğruluk değerlendirmesi}

Elde edilen kentsel tematik haritaların sayısal değerlendirmeleri uzaktan algılamada doğruluk değerlendirmede sıklıkla kullanılan hata matrisleri ile gerçekleştirilmiştir. Sınıflandırma doğruluğunu ölçebilmek için hata matrislerinden genel doğruluk ve genel kappa katsayı değerleri hesaplanmıştır. Ek olarak, her bir sınıf doğruluğunu ölçmek için üretici doğruluğu, kullanıcı doğruluğu ve her bir kategori için kappa değerleri hesaplanmıştır. Sınıflandırma doğruluğunu belirleyen genel doğruluk, doğru olarak sınıflandırılan piksel sayısının toplam piksel sayısına bölünmesiyle hesaplanır. Genel kappa değerleri genel uyuşumu ölçer. Diğer taraftan, üretici doğruluğu bir sınıfın ne kadar iyi haritalandığını, kullanıcı doğruluğu ise belirli bir sınıfın sınıflandırma güvenilirliğini gösterir. Her bir kategori için kappa her sınıfın uyuşumunu ölçer.

Her iki makine öğrenme algoritma sonuçları daha sonra s1nıflandırıcı çiftlerinin farklarının istatistiki önem farklılıklarını değerlendirmede kullanılan McNemar testi kullanarak kıyaslanmıştır. McNemar testi aşağıdaki formül kullanılarak hesaplanabilir (Foody 2004):

$X^{2}=\frac{\left(\left|f_{12}-f_{21}\right|-1\right)^{2}}{f_{12}+f_{21}}$ 
Eşitlikte $\mathrm{f}_{12}$ birinci sınıflandırıcı tarafından doğru şekilde s1nıflandırılan ama ikinci sınıflandırıcı ile yanlış sınıflandırılan piksellerin sayısını ifade ederken, $\mathrm{f}_{21}$ ikinci sınıflandırıcı kullanarak doğru sınıflandırılan fakat birinci sınıflandırıcı ile yanlış sınıflandırılan piksellerin sayısını ifade eder.

\section{Bulgular ve tartışma}

RO ve DVM sınıflandırıcıları kullanarak üretilen kentsel tematik haritalar Şekil 2'de sunulmuştur. Sınıflandırma sonuçları görsel olarak değerlendirildiğinde, kentsel tematik haritaların oldukça başarılı üretildiği söylenebilir. RO sınıflandırması için elde edilen hata matrisleri test alanları I, II, III ve IV için sırasıyla Tablo 1, 2, 3 ve 4'te sunulmuştur. Diğer taraftan, DVM sınıflandırması için elde edilen hata matrisle- ri, test alanları I, II, III ve IV için sırasıyla tablo 5, 6, 7 ve 8'te sunulmuştur. Elde edilen sonuçlar her iki sınıflandırma tekniği kullanılarak her bir test alanında arazi-örtüsü haritalarının \%89'dan daha yüksek genel doğruluk değerleriyle oldukça hassas bir şekilde üretildiğini göstermektedir.

RO sinıflandirıcı kullanarak, genel doğruluklar I. Test alanı için \%93.99, II. Test alanı için \%90.22, III. Test alanı için \%96.38 ve IV test alanı için \%89.92 olarak hesaplanmıştır. Kappa katsayıları test alanları I, II, III ve IV için sırasıyla 0.9298, 0.8826, 0.9566, ve 0.8790 olarak bulunmuştur. Diğer taraftan, DVM sinıflandırıcı kullanarak test alanları I, II, III ve IV için genel doğruluklar sirasıyla \%94.00, \%92.68, $\% 96.07$, ve \%91.98 olarak hesaplanmıştır. Kappa katsayılar1 test alanları I, II, III ve IV için sirasıyla 0.9300, 0.9122, 0.9528 ve 0.9038 olarak bulunmuştur.

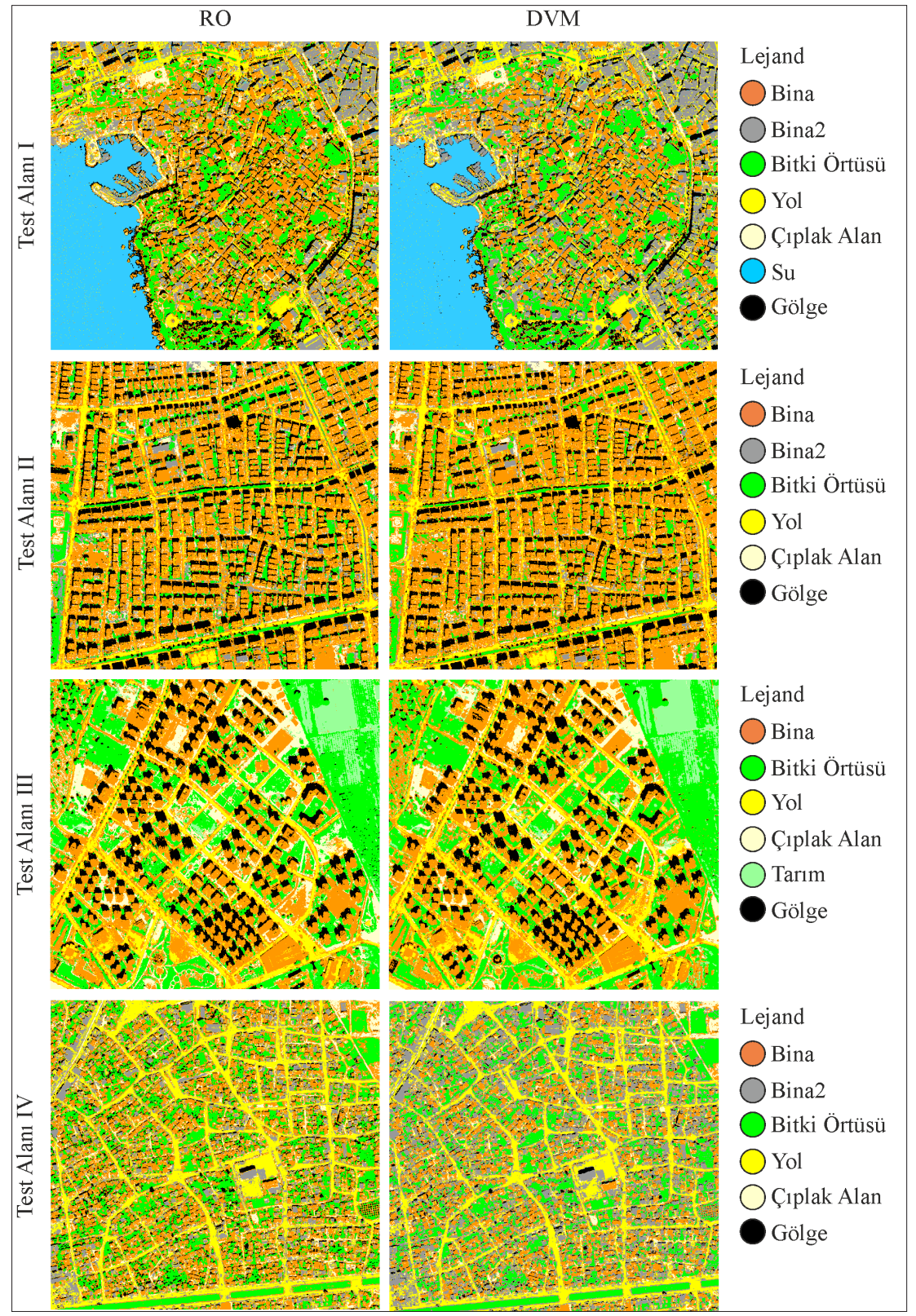

Şekil 2: Test alanı I, Test alanı II, Test alanı III ve Test Alanı IV için RO ve DVM sınıflandırma sonuçları 
Test alanlarındaki kentsel tematik haritalar kıyaslandığında her iki sınıflandırma tekniği kullanılarak en hassas haritaların Test Alanı III için üretildiği görülmektedir. Bu test alanı planlı bir yerleşim olduğundan düzenli gelişmiştir. Bu alandaki binalar düzenli ve geniş aralıklıdır. Ayrıca, diğer test alanlarıyla kıyaslandığında belirlenmiş sınıflar spektral olarak birbirinden farklıdır ve sınıflar arası spektral karışıklık azdır. Test alanı I için elde edilen tematik haritalar da oldukça doğrudur. Ancak bu test alanındaki genel doğruluk Test Alanı III ile karşılaştırıldığında biraz daha düşüktür, çünkü bu test alanındaki binalar oldukça küçük ve birbirine yakındır. Diğer taraftan, Test Alanı II için görece daha düşük doğruluklar elde edilmiștir. Bu test alanı yoğun kent dokusu içermektedir ve bu alandaki binaların çoğu beton çatılıdır, bu durum bina sınıfının yol ve çıplak alan sınıflarıyla karışmasına neden olabilmektedir. Bunların yanında, sinıflandirma sirasında bu test alanının dezavantajı, çatılarda bulunan güneş enerji su 1sıtma sistemlerinin varlığ 1 ve bunların sınıflandırma işleminde sorunlara yol açabilmesidir. Her iki sınıflandırıcıyı kullanarak en düşük doğruluklar plansız yerleşim bölgesi olan Test Alanı IV için elde edilmiştir. Bu test alanındaki binaların birbirine çok yakın olması ve binaların boyutlarının oldukça küçük olması sınıflandırma doğruluğunun düşmesine sebep olmaktadır.

Tablo 1: I. Test alanı için RO sınıflandırma sonucunun hata matrisi

\begin{tabular}{|c|c|c|c|c|c|c|c|c|}
\hline \multicolumn{9}{|c|}{ Yer Doğruluğu } \\
\hline Sinıf & Bina & Bina2 & Bitki Örtüsü & Yol & Çıplak Alan & $\mathrm{Su}$ & Gölge & Toplam \\
\hline Bina & 999 & 31 & 4 & 16 & 21 & 1 & 5 & 1077 \\
\hline Bina2 & 0 & 835 & 0 & 109 & 27 & 0 & 0 & 971 \\
\hline Bitki Örtüsü & 0 & 0 & 993 & 0 & 0 & 0 & 0 & 993 \\
\hline Yol & 0 & 114 & 0 & 868 & 51 & 1 & 0 & 1034 \\
\hline Çıplak Alan & 1 & 6 & 0 & 7 & 901 & 0 & 0 & 915 \\
\hline $\mathrm{Su}$ & 0 & 2 & 0 & 0 & 0 & 993 & 5 & 1000 \\
\hline Gölge & 0 & 12 & 3 & 0 & 0 & 5 & 990 & 1010 \\
\hline Toplam & 1000 & 1000 & 1000 & 1000 & 1000 & 1000 & 1000 & 7000 \\
\hline Üretici Doğruluğu (\%) & 99.90 & 83.50 & 99.30 & 86.80 & 90.10 & 99.30 & 99.00 & \\
\hline Kullanıcı Doğruluğu (\%) & 92.76 & 85.99 & 100.00 & 83.95 & 98.47 & 99.30 & 98.02 & \\
\hline
\end{tabular}

Genel Doğruluk (\%): 93.99; Genel Kappa: 0.9298

Tablo 2: II. Test alanı için RO sınıflandırma sonucunun hata matrisi

\begin{tabular}{|c|c|c|c|c|c|c|c|}
\hline \multicolumn{8}{|c|}{ Yer Doğruluğu } \\
\hline Sinif & Bina & Bina2 & Bitki Örtüsü & Yol & Çıplak Alan & Gölge & Toplam \\
\hline Bina & 872 & 9 & 0 & 226 & 157 & 7 & 1271 \\
\hline Bina2 & 2 & 965 & 1 & 4 & 29 & 0 & 1001 \\
\hline Bitki Örtüsü & 0 & 0 & 999 & 0 & 0 & 0 & 999 \\
\hline Yol & 54 & 1 & 0 & 770 & 0 & 0 & 825 \\
\hline Çıplak Alan & 68 & 25 & 0 & 0 & 814 & 0 & 907 \\
\hline Gölge & 4 & 0 & 0 & 0 & 0 & 993 & 997 \\
\hline Toplam & 1000 & 1000 & 1000 & 1000 & 1000 & 1000 & 6000 \\
\hline Üretici Doğruluğu (\%) & 87.20 & 96.50 & 99.90 & 77.00 & 81.40 & 99.30 & \\
\hline Kullanıcı Doğruluğu (\%) & 68.61 & 96.40 & 100.00 & 93.33 & 89.75 & 99.60 & \\
\hline
\end{tabular}

Genel Doğruluk (\%): 90.22; Genel Kappa: 0.8826

Tablo 3: III. Test alanı için RO sınıflandırma sonucunun hata matrisi

\begin{tabular}{|c|c|c|c|c|c|c|c|}
\hline \multicolumn{8}{|c|}{ Yer Doğruluğu } \\
\hline Sinif & Bina & Bitki Örtüsü & Yol & Çıplak Alan & Tarım & Gölge & Toplam \\
\hline Bina & 904 & 0 & 88 & 14 & 0 & 14 & 1020 \\
\hline Bitki Örtüsü & 0 & 1000 & 0 & 0 & 1 & 0 & 1001 \\
\hline Yol & 80 & 0 & 912 & 0 & 0 & 0 & 992 \\
\hline Çıplak Alan & 10 & 0 & 0 & 985 & 3 & 0 & 998 \\
\hline Tarım & 0 & 0 & 0 & 1 & 996 & 0 & 997 \\
\hline Gölge & 6 & 0 & 0 & 0 & 0 & 986 & 992 \\
\hline Toplam & 1000 & 1000 & 1000 & 1000 & 1000 & 1000 & 6000 \\
\hline Üretici Doğruluğu (\%) & 90.40 & 100.00 & 91.20 & 98.50 & 99.60 & 98.60 & \\
\hline Kullanıcı Doğruluğu (\%) & 88.63 & 99.90 & 91.94 & 98.70 & 99.90 & 99.40 & \\
\hline
\end{tabular}

Genel Doğruluk (\%): 96.38; Genel Kappa: 0.9566 
Tablo 4: IV. Test alanı için RO sınıflandırma sonucunun hata matrisi

\begin{tabular}{|c|c|c|c|c|c|c|c|}
\hline \multicolumn{8}{|c|}{ Ground Truth } \\
\hline Sinıf & Bina & Bina2 & Bitki Örtüsü & Yol & Çıplak Alan & Gölge & Toplam \\
\hline Bina & 940 & 17 & 1 & 0 & 216 & 0 & 1174 \\
\hline Bina2 & 0 & 818 & 0 & 56 & 89 & 0 & 963 \\
\hline Bina2 & 0 & 0 & 999 & 0 & 0 & 0 & 999 \\
\hline Yol & 0 & 148 & 0 & 944 & 1 & 0 & 1093 \\
\hline Çıplak Alan & 60 & 7 & 0 & 0 & 694 & 0 & 761 \\
\hline Gölge & 0 & 10 & 0 & 0 & 0 & 1000 & 1010 \\
\hline Toplam & 1000 & 1000 & 1000 & 1000 & 1000 & 1000 & 6000 \\
\hline Üretici Doğruluğu (\%) & 94.00 & 81.80 & 99.90 & 94.40 & 69.40 & 100.00 & \\
\hline Kullanıcı Doğruluğu (\%) & 80.07 & 84.94 & 100,00 & 86.37 & 91.20 & 99.01 & \\
\hline
\end{tabular}

Tablo 5: I. Test alanı için DVM sınıflandırma sonucunun hata matrisi.

\begin{tabular}{|c|c|c|c|c|c|c|c|c|}
\hline \multicolumn{9}{|c|}{ Yer Doğruluğu } \\
\hline Sinif & Bina & Bina2 & Bitki Örtüsü & Yol & Çıplak Alan & $\mathrm{Su}$ & Gölge & Toplam \\
\hline Bina & 999 & 6 & 2 & 3 & 6 & 0 & 7 & 1023 \\
\hline Bina2 & 0 & 836 & 5 & 107 & 18 & 0 & 12 & 978 \\
\hline Bitki Örtüsü & 0 & 0 & 992 & 0 & 0 & 0 & 0 & 992 \\
\hline Yol & 0 & 144 & 0 & 887 & 85 & 1 & 1 & 1118 \\
\hline Çıplak Alan & 1 & 1 & 0 & 3 & 891 & 0 & 0 & 896 \\
\hline $\mathrm{Su}$ & 0 & 0 & 0 & 0 & 0 & 998 & 3 & 1001 \\
\hline Gölge & 0 & 13 & 1 & 0 & 0 & 1 & 977 & 992 \\
\hline Toplam & 1000 & 1000 & 1000 & 1000 & 1000 & 1000 & 1000 & 7000 \\
\hline Üretici Doğruluğu (\%) & 99.90 & 83.60 & 99.20 & 88.70 & 89.10 & 99.80 & 97.70 & \\
\hline Kullanıcı Doğruluğu (\%) & 97.65 & 85.48 & 100.00 & 79.34 & 99.44 & 99.70 & 98.49 & \\
\hline
\end{tabular}

Genel Doğruluk (\%): 94.00; Genel Kappa: 0.9300

Tablo 6: II. Test alanı için DVM sınıflandırma sonucunun hata matrisi.

\begin{tabular}{|c|c|c|c|c|c|c|c|}
\hline \multicolumn{8}{|c|}{ Yer Doğruluğu } \\
\hline Sinif & Bina & Bina2 & Bitki Örtüsü & Yol & Çıplak Alan & Gölge & Toplam \\
\hline Bina & 881 & 8 & 0 & 154 & 91 & 6 & 1140 \\
\hline Bina2 & 0 & 965 & 0 & 0 & 27 & 0 & 992 \\
\hline Bitki Örtüsü & 0 & 0 & 1000 & 0 & 0 & 0 & 1000 \\
\hline Yol & 73 & 1 & 0 & 839 & 0 & 0 & 913 \\
\hline Çıplak Alan & 41 & 26 & 0 & 0 & 882 & 0 & 949 \\
\hline Gölge & 5 & 0 & 0 & 7 & 0 & 994 & 1006 \\
\hline Toplam & 1000 & 1000 & 1000 & 1000 & 1000 & 1000 & 6000 \\
\hline Üretici Doğruluğu (\%) & 88.10 & 96.50 & 100.00 & 83.90 & 88.20 & 99.40 & \\
\hline Kullanıcı Doğruluğu (\%) & 77.28 & 97.28 & 100.00 & 91.89 & 92.94 & 98.81 & \\
\hline
\end{tabular}

Genel Doğruluk (\%): 92.68; Genel Kappa: 0.9122

Tablo 7: III. Test alanı için DVM sınıflandırma sonucunun hata matrisi.

\begin{tabular}{|c|c|c|c|c|c|c|c|}
\hline \multicolumn{8}{|c|}{ Yer Doğruluğu } \\
\hline Sinıf & Bina & Bitki Örtüsü & Yol & Çıplak Alan & Tarım & Gölge & Toplam \\
\hline Bina & 890 & 6 & 73 & 38 & 1 & 5 & 1013 \\
\hline Bitki Örtüsü & 0 & 994 & 0 & 0 & 0 & 0 & 994 \\
\hline Yol & 80 & 0 & 927 & 0 & 0 & 0 & 1007 \\
\hline Çıplak Alan & 13 & 0 & 0 & 962 & 3 & 0 & 978 \\
\hline Tarım & 1 & 0 & 0 & 0 & 996 & 0 & 997 \\
\hline Gölge & 16 & 0 & 0 & 0 & 0 & 995 & 1011 \\
\hline Toplam & 1000 & 1000 & 1000 & 1000 & 1000 & 1000 & 6000 \\
\hline Üretici Doğruluğu (\%) & 89.00 & 99.40 & 92.70 & 96.20 & 99.60 & 99.50 & \\
\hline Kullanıcı Doğruluğu (\%) & 87.86 & 100.00 & 92.06 & 98.36 & 99.90 & 98.42 & \\
\hline
\end{tabular}


Tablo 8: IV. Test alanı için DVM sınıflandırma sonucunun hata matrisi

\begin{tabular}{|c|c|c|c|c|c|c|c|}
\hline \multicolumn{8}{|c|}{ Yer Doğruluğu } \\
\hline Sinif & Bina & Bina2 & Bitki Örtüsü & Yol & Çıplak Alan & Gölge & Toplam \\
\hline Bina & 960 & 3 & 0 & 0 & 142 & 0 & 1105 \\
\hline Bina2 & 3 & 865 & 5 & 39 & 95 & 6 & 1013 \\
\hline Bitki Örtüsü & 0 & 0 & 995 & 0 & 0 & 0 & 995 \\
\hline Yol & 0 & 123 & 0 & 961 & 19 & 0 & 1103 \\
\hline Çıplak Alan & 37 & 6 & 0 & 0 & 744 & 0 & 787 \\
\hline Gölge & 0 & 3 & 0 & 0 & 0 & 994 & 997 \\
\hline Toplam & 1000 & 1000 & 1000 & 1000 & 1000 & 1000 & 6000 \\
\hline Üretici Doğruluğu (\%) & 96.00 & 86.50 & 99.50 & 96.10 & 74.40 & 99.40 & \\
\hline Kullanıcı Doğruluğu (\%) & 86.88 & 85.39 & 100.00 & 87.13 & 94.54 & 99.70 & \\
\hline
\end{tabular}

Genel Doğruluk (\%): 91.98; Genel Kappa: 0.9038

Dört test alanı için her bir arazi-örtü sınıfının RO ve DVM sınıflandırıcılarını kullanarak bulunan üretici doğruluğu, kullanıcı doğruluğu ve her bir kategori kappa değerleri sırasıyla Tablo 9 ve 10 'da verilmiştir. Çoğu arazi-örtü sınıfları için üretici ve kullanıcı doğruluklarının \%75 değerinin üzerinde hesaplanması, RO ve DVM sinıflandırıcılarının WorldView-2 uydu görüntülerinden kentsel tematik haritalamadaki başarılarını göstermektedir. Her bir sınıf için elde edilen üretici doğruluğu, kullanıcı doğruluğu ve her bir kategori kappa değerlerine dayanarak en doğru haritalanan arazi-örtüsü sınıfları, farklı spektral karakteristiklerinden dolay1, bitki örtüsü ve gölgedir. Diğer taraftan, Bina/Bina2 ve yol sınıfları bu arazi-örtü tiplerine ait piksellerin spektral değişkenliğinden ve diğer arazi-örtüsü sınıflarıyla benzer spektral karakterlerinden dolayı daha az doğrulukla haritalanmıştır. Daha ayrıntılı bilgi vermek gerekirse, birinci test alanı için bitki örtüsü ve su sınıfları en yüksek doğrulukla sınıflandırılırken, yol ve bina2 sinıfları en düşük doğrulukla sınıflandırılmıştır. İkinci test alanında bitki örtüsü ve gölge sınıfları en doğru şekilde sınıflandırılırken, bina, çıplak alan ve yol sınıfları daha az doğrulukla sınıflandırılmıştır. Benzer şekilde üçüncü test alanında en doğru sınıflandırılan sınıflar bitki örtüsü, tarımsal alan ve gölgeler iken, en az doğrulukla sinıflandırılan sınıflar bina ve yoldur. Son olarak, dördüncü test alanı için de bitki örtüsü ve gölge sınıfları en yüksek doğrulukla sınıflandırılırken, bina ve bina2 sınıfları en düşük doğrulukla sınıflandırılmıştır.

Tablo 9: RO sınıflandırma sonuçlarının Test Alanları I, II, III ve IV için genel ve her bir kategori doğruluk ölçümlerinin karşılaştırılması

\begin{tabular}{|c|c|c|c|c|c|c|c|c|c|c|c|c|}
\hline & \multicolumn{3}{|c|}{ Test Alanı I } & \multicolumn{3}{|c|}{ Test Alanı II } & \multicolumn{3}{|c|}{ Test Alanı III } & \multicolumn{3}{|c|}{ Test Alanı IV } \\
\hline & ÜD & $\mathrm{KD}$ & $\mathrm{K}$ & ÜD & $\mathrm{KD}$ & $\mathrm{K}$ & ÜD & $\mathrm{KD}$ & $\mathrm{K}$ & ÜD & $\mathrm{KD}$ & $\mathrm{K}$ \\
\hline & $(\%)$ & $(\%)$ & $(\%)$ & $(\%)$ & $(\%)$ & $(\%)$ & $(\%)$ & $(\%)$ & $(\%)$ & $(\%)$ & $(\%)$ & $(\%)$ \\
\hline Bina & 99.90 & 92.76 & 91.55 & 87.20 & 68.61 & 63.38 & 90.40 & 88.63 & 86.73 & 94.00 & 80.07 & 76.75 \\
\hline Bina2 & 83.50 & 85.99 & 83.66 & 96.50 & 96.40 & 95.80 & - & - & - & 81.80 & 84.94 & 82.43 \\
\hline Bitki Örtüsü & 99.30 & 100.00 & 100.00 & 99.90 & 100.00 & 100.00 & 100.00 & 99.90 & 99.88 & 99.90 & 100.00 & 100.00 \\
\hline Yol & 86.80 & 83.95 & 81.27 & 77.00 & 93.33 & 92.22 & 91.20 & 91.94 & 90.59 & 94.40 & 86.37 & 84.10 \\
\hline Çıplak Alan & 90.10 & 98.47 & 98.21 & 81.40 & 89.75 & 88.04 & 98.50 & 98.70 & 98.48 & 69.40 & 91.20 & 89.73 \\
\hline Tarım & - & - & - & - & - & - & 99.60 & 99.90 & 99.88 & - & - & - \\
\hline $\mathrm{Su}$ & 99.30 & 99.30 & 99.18 & - & - & - & - & - & - & - & - & - \\
\hline Gölge & 99.00 & 98.02 & 97.69 & 99.30 & 99.60 & 99.53 & 98.60 & 99.40 & 99.29 & 100.00 & 99.01 & 98.84 \\
\hline GD (\%) & & 93.99 & & & 90.22 & & & 96.38 & & & 89.92 & \\
\hline GK & & 0.9298 & & & 0.8826 & & & 0.9566 & & & 0.8790 & \\
\hline
\end{tabular}

GD: Genel Doğruluk, GK: Genel Kappa, ÜD: Üretici Doğruluğu, KD: Kullanıcı Doğruluğu, K Kategori Kappa Değeri

Tablo 10: DVM sınıflandırma sonuçlarının Test Alanları I, II, III ve IV için genel ve her bir kategori doğruluk ölçümlerinin karşılaştırılması

\begin{tabular}{|c|c|c|c|c|c|c|c|c|c|c|c|c|}
\hline & \multicolumn{3}{|c|}{ Test Alanı I } & \multicolumn{3}{|c|}{ Test Alanı II } & \multicolumn{3}{|c|}{ Test Alanı III } & \multicolumn{3}{|c|}{ Test Alanı IV } \\
\hline & ÜD & $\mathrm{KD}$ & $\mathrm{K}$ & ÜD & $\mathrm{KD}$ & K & ÜD & $\mathrm{KD}$ & $\mathrm{K}$ & ÜD & $\mathrm{KD}$ & K \\
\hline & $(\%)$ & $(\%)$ & $(\%)$ & $(\%)$ & $(\%)$ & $(\%)$ & $(\%)$ & $(\%)$ & $(\%)$ & $(\%)$ & $(\%)$ & $(\%)$ \\
\hline Bina & 99.90 & 97.65 & 97.26 & 88.10 & 77.28 & 73.49 & 89.00 & 87.86 & 85.83 & 96.00 & 86.88 & 84.69 \\
\hline Bina2 & 83.60 & 85.48 & 83.06 & 96.50 & 97.28 & 96.82 & - & - & - & 86.50 & 85.39 & 82.95 \\
\hline Bitki Örtüsü & 99.20 & 100.00 & 100.00 & 100.00 & 100.00 & 100.00 & 99.40 & 100.00 & 100.00 & 99.50 & 100.00 & 100.00 \\
\hline Yol & 88.70 & 79.34 & 75.89 & 83.90 & 91.89 & 90.54 & 92.70 & 92.06 & 90.73 & 96.10 & 87.13 & 84.98 \\
\hline Çıplak Alan & 89.10 & 99.44 & 99.35 & 88.20 & 92.94 & 91.76 & 96.20 & 98.36 & 98.09 & 74.40 & 94.54 & 93.63 \\
\hline Tarım & - & - & - & - & - & - & 99.60 & 99.90 & 99.88 & - & - & - \\
\hline $\mathrm{Su}$ & 99.80 & 99.70 & 99.65 & - & - & - & - & - & - & - & - & - \\
\hline Gölge & 97.70 & 98.49 & 98.24 & 99.40 & 98.81 & 98.61 & 99.50 & 98.42 & 98.15 & 99.40 & 99.70 & 99.65 \\
\hline GD (\%) & & 94.00 & & & 92.68 & & & 96.07 & & & 91.98 & \\
\hline GK & & 0.9300 & & & 0.9122 & & & 0.9528 & & & 0.9038 & \\
\hline
\end{tabular}

GD: Genel Doğruluk, GK: Genel Kappa, ÜD: Üretici Doğruluğu, KD: Kullanıcı Doğruluğu, K Kategori Kappa Değeri 
Sınıflandırıcı çiftleri arasındaki McNemar test sonuçları Tablo 11'de sunulmuştur. Bu testlere göre I., II., III. ve IV. test alanlarındaki $\mathrm{X}^{2}$ değerleri sırasıyla $0.00,69.71,1.51$, ve 35.51 olarak hesaplanmıştır. I. ve III. test aralarında $X^{2}$ değerleri 3.84'ten daha az olarak hesaplanmıştır. Bu nedenle RO ve DVM sinıflandırıcıların performansları bu test alanları için neredeyse eşittir. Diğer taraftan II. ve IV. test alanları için $\mathrm{X}^{2}$ değerleri 3.84'ten daha büyüktür bu da DVM sınıflandırıcının RO yerine tercih edildiğinde $\% 95$ güven aralığında önemli ölçüde doğruluk artışı olduğunu ortaya koymaktadır.

\section{Sonuçlar}

$\mathrm{Bu}$ çalışmada RO ve DVM sınıflandırma tekniklerinin WorldView-2 uydu görüntülerinden kentsel tematik haritaların çıkarılmasındaki performansları izlenmiş ve karşılaştırılmıştır. Sınıflandırma algoritmaları, keskinleştirilmiş WorldView-2 uydu görüntüleri kullanılarak farklı kentsel karakterler gösteren test alanlarına uygulanmıştır. Sonuçlar göstermiştir ki, kentsel tematik haritalar her iki makine öğrenme algoritması kullanılarak oldukça hassas şekilde üretilebilir. En hassas sınıflandırma sonuçları düzenli gelişmiş yeni konut dokuları için (III. test alanı) elde edilmiştir, çünkü bu test alanındaki binalar seyrek olarak konumlanmış ve boyutları görece büyüktür. İkinci en iyi sonuçlar geleneksel ketsel dokusu olan (I. test alanı) test alanı için elde edilmiştir. Bu test alanında binaların boyutları küçüktür ve düzenli bir deseni yoktur. Ancak, bu test alanının avantajı, sınıfların spektral olarak ayrılabilirliğidir. Her ne kadar II. test alanı düzenli gelişmiş şehir dokusunu içerse de, bu test alanının sınıflandırma doğruluğu üçüncü test alanı kadar yüksek değildir. Bu durumda, sınıflandırma doğruluğundaki düşüklük farklı sebeplerden kaynaklanabilir; (i) sınıfların spektral olarak benzerliği, (ii) yoğun kent dokusu, (iii) bina çatılarında güneş enerjisi su 1sıtma sistemlerinin bulunması. Son olarak, en düşük sınıflandırma doğruluğu plansız kent dokusuna sahip dördüncü test alanı için elde edilmiştir. Bu test alanında binalar çok küçük boyutta ve birbirlerine çok yakındir.

DVM ve RO sınıflandırıcıları I. ve III. test alanları için genel doğruluk bakımından neredeyse eşit sonuç vermiştir. Ancak DVM sınıflandırıcısı genel hassasiyet bakımından II. ve IV. test alanı için biraz daha iyi sonuçlar üretmiştir. Her ne kadar DVM sınıflandırıcısı göreceli olarak daha yüksek doğruluk sağlasa da RO sınıflandırıcısının sonuçları da oldukça iddialıdır. Sonuç olarak, her iki makine öğrenme algoritması da WorldView-2 uydu görüntülerinden kentsel alan örtüsü haritalamasında etkin olarak kullanılabilir.

\section{Kaynaklar}

Akar Ö., Güngör O., (2012), Classification of multispectral images using Random Forest Algorithm, Journal of Geodesy and Geoinformation, 1(2), 105-112, doi: 10.9733/jgg.241212.1.

Berger C., Voltersen M., Hese S., Walde I., Schmullius C., (2013). Robust extraction of urban land cover information from HSR multi-spectral and Lidar data, IEEE Journal of Selected Topics in Applied Earth Observation and Remote Sensing, 6(5), 21962211, doi: 10.1109/JSTARS.2013.2252329.

Breiman L. (2001), Random Forests, Machine Learning, 45, 5-32, doi: 10.1023/A:1010933404324,

Breiman L., (1996), Bagging Predictors, Machine Learning, 24,123-140, doi: 10.1007/BF00058655.

Chen Z., Wang G., Liu J., (2012), A modified objectoriented classification algorithm and its application in high-resolution remote-sensing imagery, International Journal of Remote Sensing, 33(10), 3048-3062., doi: 10.1080/01431161.2011.625055.

Dalponte M., Orka H. O., Gobakken T., Gianelle D., Naesset E., (2013), Tree species classification in Boreal forests with hyperspectral data, IEEE Transactions on Geoscience and Remote Sensing, 51(5), 2632-2645, doi: 10.1109/ TGRS.2012.2216272.

Foody G. M., (2004), Thematic Map Comparison: Evaluating the Statistical Significance of Differences in Classification Accuracy, Photogrammetric Engineering and Remote Sensing 70(5), 627-633, doi: 10.14358/PERS.70.5.627.

Gislason P. O., Benediktsson J. A., Sveinson J. R., (2006), Random forests for land cover classification, Pattern Recognition Letters, 27(4), 294-300, doi: 10.1016/j.patrec.2005.08.011.

Guan H., Li J., Chapman M., Deng F., Ji Z., Yang X., (2013), Integration of orthoimagery and Lidar data for objectbased urban thematic mapping using random forests, International Journal of Remote Sensing, 34(14), 5166-5186, doi: 10.1080/01431161.2013.788261.

Huang C., Davis L. S., Townshend J. R. G., (2002), An assessment of support vector machines for land cover classification, International Journal of Remote Sensing, 23(4), 725-749, doi: 10.1080/01431160110040323.

Huang X., Zhang L., Li P., (2007), Classification and extraction of spatial features in urban areas using high-resolution multispectral imagery, IEEE Geoscience and Remote Sensing Letters, 4(2), 260-264, doi: 10.1109/LGRS.2006.890540.

Jakimow B., Oldenburg C., Rabe A., Waske B., van der Linden S., Hostert P., (2012), Manual for Application: ImageRF (1.1), Universtat Bonn and Humboldt Universitat zu Berlin, Almanya.

Kavzoglu T., Colkesen I., (2009), A kernel functions analysis for support vector machines for land cover classification, International Journal of Applied Earth Observation and Geoinformation, 11, 352-359, doi: 10.1016/j.jag.2009.06.002.

Koc-San D., (2013), Evaluation of different classification techniques for the detection of glass and plastic greenhouses

Tablo 11: Test Alanları I, II, III, ve IV'de DVM ve RO sınıflandırıcılarının karşılaştırılması için McNemar testi sonuçları

\begin{tabular}{|c|c|c|c|c|c|c|c|}
\hline Test Alanı & Sınıflandırma Çiftleri & $f_{11}$ & $f_{12}$ & $f_{21}$ & $f_{22}$ & Total & $\mathrm{X}^{2}$ \\
\hline I & DVM - RO & 6458 & 122 & 121 & 299 & 7000 & 0.00 \\
\hline II & DVM - RO & 5332 & 229 & 81 & 358 & 6000 & 69.71 \\
\hline III & DVM - RO & 5666 & 98 & 117 & 119 & 6000 & 1.51 \\
\hline IV & DVM - RO & 5244 & 275 & 151 & 330 & 6000 & 35.51 \\
\hline
\end{tabular}

${ }_{11}$ : her iki sınıflandırıcı ile doğru şekilde sınıflandırılan piksel sayısı; $f_{12}$ : birinci sınıflandırıcı ile doğru ancak ikinci sınıflandırıcı ile hatalı sınıflandırılan piksel sayısı; $f_{21}$ : ikinci sınıflandırıcı ile doğru ancak birinci sınıflandırıcı ile hatalı sınıflandırılan piksel sayısı; $f_{22}$ : her iki sınıflandırıcı ile hatalı sınıflandırılan piksel sayısı $\% 95$ güven aralığındaki anlamlı farklar $\left(\mathrm{X}^{2} \geq 3.84\right)$ koyu punto ile gösterilmiştir. 
from WorldView-2 satellite imagery, Journal of Applied Remote Sensing, 7(1), 073553-1-20, doi: 10.1117/1.JRS.7.073553.

OumarZ., Mutanga O.,(2013), Using World View-2 bands andindices to predict bronze bug (Thaumastocoris peregrinus) damage in plantation forests, International Journal of Remote Sensing, 34(6), 2236-2249, doi: 10.1080/01431161.2012.743694.

Pacifici F., Chini M., Emery W. J., (2009), A neural network approach using multi-scale textural metrics from very high-resolution panchromatic imagery for urban land-use classification, Remote Sensing of Environment, 113(2009), 1276-1292, doi: 10.1016/j.rse.2009.02.014.

Pal M., (2005), Random Forest Classifier for Remote Sensing Classification, International Journal of Remote Sensing, 26(1), 217-222, doi: 10.1080/01431160412331269698.

Palsson F., Sveinsson J.R., Benediktsson J. A., Anaes H., (2012), Classification of pansharpened urban satellite images, IEEE Journal of Selected Topics in Applied Earth Observations and Remote Sensing, 5(1), 281-297, doi: 10.1109/ JSTARS.2011.2176467.

PCI Software Users Manual, (2013), PCI Geomatics Enterprises Inc., Richmond Hill, Ontario, Kanada.

Rabe A., Van der Linden S., Hostert P., (2010), ImageSVM, Version 2.1, http:/www.hu-geomatics.de [Erişim 1 May 2013].

Ridd M. K., (1995), Exploring a VIS (vegetation-impervioussurface-soil) model for urban ecosystem analysis through remote sensing: Comparative anatomy for cities, International Journal of Remote Sensing, 16(12), 2165-2185, doi: 10.1080/01431169508954549.

Rodriguez-Galiano V. F., Chica-Rivas M., (2012), Evaluation of different machine learning methods for land cover mapping of a Mediterranean area using multi-seasonal Landsat images and Digital Terrain Models, International Journal of Digital Earth, doi: 10.1080/17538947.2012.748848.

Rodriguez-Galiano V. F., Ghimire B., Rogan J., Chica-Olmo M. Rigol-Sanchez J. P., (2012), An assessment of the effectiveness of a random forest classifier for land-cover classification, ISPRS Journal of Photogrammetry and Remote Sensing, 67, 93-104, doi: 10.1016/j.isprsjprs.2011.11.002.

Sesnie S. E., Finegan B., Gessler P. E., Thessler S., Bendana Z.
R., Smith A. M. S., (2010), The multispectral separability of Costa Rican rainforest types with support vector machines and Random Forest decision trees, International Journal of Remote Sensing, 31(11), 2885-2909, doi: 10.1080/01431160903140803.

Updike T., Comp C., (2010), Radiometric use of WorldView-2 imagery, http://www. digitalglobe.com/downloads/ Radiometric_Use_of_WorldView-2_Imagery.pdf [Erişim 1 May 2013].

Van der Linden S., Rabe A., Wirth F., Suess S., Okujeni A., Hostert P., (2010), ImageSVM Classification, Manual for Application: ImageSVM, Version 2.1, Humboldt-Universitat zu Berlin, Almanya.

Vapnik, V. N., (1995), The Nature of Statistical Learning Theory, Springer-Verlag, New York, doi: 10.1007/978-1-4757-2440-0

Wang L., (2005), Support Vector Machines: Theory and Applications, Springer-Verlag, Berlin, Heidelberg.

Waske, B., Benediktsson J. A., Arnason K., Sveinsson J. R., (2009), Mapping of hyperspectral Aviris data using machine-learning algorithms, Canadian Journal of Remote Sensing, 35(S1), S106-S116, doi: 10.5589/m09-018.

Waske B., Braun M., (2009), Classifier ensembles for land cover mapping using multitemporal SAR imagery, ISPRS Journal of Photogrammetry and Remote Sensing, 64, 450-457, doi: 10.1016/j.isprsjprs.2009.01.003.

Waske B., van der Linden S., Oldenburg C., Jakimow, B., Rabe A., Hostert P., (2012), ImageRF - A user-oriented implementation for remote sensing image analysis with Random Forests, Environmental Modelling and Software, 35, 192-193, doi: 10.1016/j.envsoft.2012.01.014.

Watanachaturaporn P., Arora M. K., Varshney P. K., (2008), Multisource classification using support vector machines: an empirical comparison with decision tree and neural network classifiers, Photogrammetric Engineering and Remote Sensing, 74(2), 239-246, doi: 10.14358/PERS.74.2.239.

Welch R., (1982). Spatial resolution requirements for urban studies, International Journal of Remote Sensing, 3(2), 139-146, doi: 10.1080/01431168208948387.

Yonezawa C., (2007). Maximum likelihood classification combined with spectral angle mapper algorithm for high resolution satellite imagery, International Journal of Remote Sensing, 28(16), 3729-3737, doi: 10.1080/01431160701373713. 